\title{
EDITORIAL 14:3 LIGHT AND LIFE IN THE NEW MILLENNIUM
}

\author{
Toshio Ohshiro MD PhD \\ Japan Medical Laser Laboratory, Tokyo, Japan
}

\begin{abstract}
Dear Colleagues, Dear Friends,
Throughout my laser-related career, which spans some three decades, a fair slice from anybody's life, and in fact even before I 'found' lasers I have been fascinated with the interaction between light and life and indeed many of my editorials in the previous existence of Laser Therapy were on that theme. The Faithful Reader will remember that, in the sacred grounds of the Ise Shrine, Japan, the central shrine of the Japanese Shinto faith, on the eighth day of the eighth month, nineteen eighty-eight, at exactly eight seconds past eight o'clock in the morning, I had the honour to be in a group praying for the blessings of light and life in the new century, indeed the New Millennium.-The Chinese idiograph for 'eight' represents an opening out of life, expansion and happiness.
\end{abstract}

At that time I wrote a poem in the ancient Shigin song style, as seen in the opposite column in the original Japanese characters and which in translation reads:

New Century

Light gives life to Eden of the Earth

With toasts of tasty wine, shouting for joy.

Only healthy song can create world peace.

Dreamy scent leads us to New Century of Light.

Toshio Ohshiro

The Ise Shrine holds the Japanese Emperor's Sacred Treasures, especially the Sacred Mirror, reputedly handed down from Emperor to Emperor from Ameterasu Oomi Kami, the Sun Goddess, and traditionally the direct ancestor of the Emperors of Japan, so it was no coincidence that we were praying for world peace through the interaction of light and life in the Shrine commemorating the Sun Goddess' gift to the island of Japan.

From the Christian standpoint, the Bible says (King James Version Genesis 1);

"In the beginning, God created the heaven and the earth ........ And God said, Let there be light: and there was light." Light has come to be associated with many concepts, such as good and evil, light and shade, tone; and is inextricably linked with the production of food, the psychological degree of inner strength leading to generation and sustaining of will power, and physical strength itself.

Long before Professor Maiman oscillated his first laser, the ' $L$ ' in which stands, of course, for 'light', the Ancient Egyptians and many other Ancients were prac- ticing heliotherapy, the art and science of using the healing powers of the sun. The 'father of medicine', Hippocrates, wrote a treaty on the healing power of the sun, recommending it in the treatment of 'melancholia', and noting that the Greeks tended to be far more happy in themselves than the Northern Europeans, a fact he attributed to the greater incidence of sunshine in Greece. Today we have even given this weather-linked depression a proper medical name, seasonal adjustment disorder, or SAD.

With the fading of the great empires all the knowledge of heliotherapy faded away too, as the world entered the so-called 'dark ages', and was not till the end of the 19th century that sunshine once again featured as having medical and clinical benefits, but particularly in the north of Europe, the sun is a fickle fellow, and it was, and still is, almost impossible to schedule heliotherapy treatments due to the fast-changing weather. The development by Neils Finsen of an artificial electric-pow-

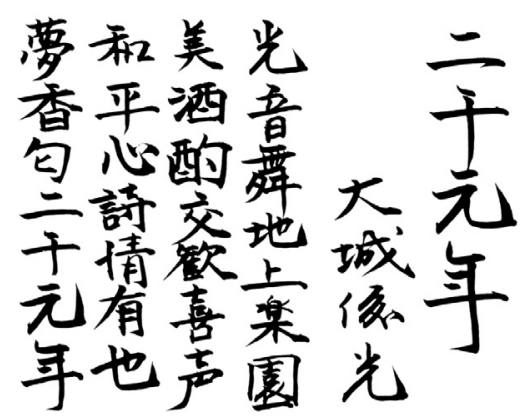

ered light source which could deliver both ultraviolet and infrared rays, and could be turned on and off with a switch, opened up the era of sunshine-independent phototherapy. Once again, however, this also faded in popularity, but then blue light phototherapy for hyperbilirubinaemia in neonates, started saving many lives in the 1950's, and there were at the same time a variety of 'over the counter' weird and wonderful 'electrotherapeutic' devices including the tried and tested infrared heat lamp.

All of these paled into insignificance with Maiman's first ruby laser, so powerful that it could drill a hole through a stack of razor blades, so someone suggested that the output power could be measured in Gillettes instead of watts! Very swiftly the medical potential of this new source of pure light was explores, 
sometimes a little over-enthusiastically, but gradually sensible treatment regimens based on sound knowledge of laser/tissue interactions were developed, and rather than being an answer in search of a problem, the laser took its proper place in the clinician's armamentarium, from general surgery to internal medicine. In the late 1960's, Endre Mester, our 'Godfather' of laser therapy opened up yet a new aspect of laser treatment with incident doses which induced athermal tissue reactions, leading to the healing of recalcitrant wounds, and the era of the therapeutic, rather than the surgical laser, was born. That was the impetus for the founding of both this journal, and the International Laser Therapy Association in 1988.

Now we are actually in the New Millennium, and the therapeutic laser has been joined by a number of noncoherent light sources, so that 'phototherapy' is now a much better catch-all name than 'laser therapy'. Despite this, our journal's masthead is still Laser Therapy since the popularity of the therapeutic laser remains very high, and other phototherapeutic light sources are still to be tested and proved, just as was the case for low reactive-level laser therapy, LLLT. So now we have broad-band visible and infrared light sources, and a new source, the light-emitting diode (LED) has become of age, (Whelan, H.T., Smits RL, Buchmann, E.V., et al. (2001). Effect of NASA Light-Emitting Diode (LED) Irradiation on Wound Healing. Journal of Clinical Laser Medicine and Surgery, 19: 305-314), delivering quasimonochromatic and clinically-useful output powers in almost any wavelength. However, we must remember our photobiology, and not get carried away with the ability to deliver therapy of many colours. Tiina Karu has demonstrated that some wavelength, far from being synergistic, cancel each other out as far as the target cell is concerned. Other researchers are showing that the correct wavelengths, applied sequentially rather than concurrently, have a very interesting synergy. We must identify and investigate these 'friendly' wavelengths. The time is fast approaching, however, when we can offer our patients a 'laser cocktail', with mixtures of appropriate wavelengths tailored to the individual patient's needs, always remembering the presence of the beneficial effects associated with the essential zone of athermal photobiomodulation which accompanies any laser surgical application, as I discussed in my article in Laser Therapy 14.1 (Ohshiro T (2005): Auto-simultaneous laser treatment. Laser Therapy, 14: 11-18), and the different penetration characteristics of each wavelength.

The most important thing about the new LEDs, apart from their very favourable price, is their quasi-monochromaticity, with extremely narrow wavebands exceeding the US FDA's requirements for laser diodes. They can therefore deliver, like their laser cousins, pure light which carries (as I have often said be- fore) its own information for the target cells encapsulated in the particular wavelength and inherent frequency of the beam. I said in an earlier 1993 editorial that laser therapy would be THE light of 21 st Century medicine, but I now believe that there is a family of light sources which can claim this title, and it is up to us to perfect them and explore further applications for the good of our patients.

One application which has attracted great interest over the last few years is the use of phototherapy to strengthen an ailing autoimmune system, and to restore homeostasis to an immunoincompetent system. Strenuous exercise has been associated with fatigue-related autoimmunoincompetency in top athletes, and I would like to direct your attention to some excellent pieces of work on this subject, and how phototherapy can favourably impact it, from a group in Hirosaki University in the north of Japan, some of which appeared in the previous issue, Laser Therapy 14:2. My sincere thanks to the Hirosaki group, now led by Professor Shigeyuki Nakaji from the School of Medicine's Department of Social Medicine, for their constant support of the journal and what it stands for. I truly feel that this area is going to be one of the most exciting applications for phototherapy in this New Millennium, and I am equally sure you'll read all about it in Laser Therapy.

\section{Official formation of IPTA}

In the new Pilot Issue 14:0 of Laser Therapy, Professor Hayk Arakelyan pointed out in an open letter that a solid and democratic society was required, fully dedicated to all aspects of phototherapy and photobiomodulation, and he went on to suggest a revival of the International Laser Therapy Association, ILTA. However, in the latest Newsletter of the World Federation of Societies for Laser Medicine and Surgery (WFSLMS), Professor Arakelyan pointed out that the use of the name ILTA was not appropriate, as the original ILTA was one of the societies which merged in 1994 to form the World Association for Laser Therapy (WALT), so 'ILTA' was, legally speaking, actually part of 'WALT'. He then discussed the widespread use of therapeutic light sources, not only therapeutic lasers but also non-laser light sources, and arrived at the much broader term of 'phototherapy'. Accordingly, he suggested that the new society should be called the International Phototherapy Association, under the acronym 'IPTA'. A group of interested parties, both international and Japanese, concurred, and a steering committee was established for the formation of IPTA and the planning of the first IPTA meeting. In a subsequent meeting of this IPTA Steering Committee, Laser Therapy was tentatively suggested as the official journal of the IPTA, which will be confirmed by the full democratic process in the near future. 